\title{
Judicialização do acesso de idosos ao Sistema Único de Saúde - SUS e Sistema Único de Assistência Social - SUAS
}

Laís Cristina Barbosa dos SANTOS: Faculdade de Saúde Pública - FSP, Universidade de São Paulo - USP. ORCID: https://orcid.org/0000-0002-6540-3658

Brunna Verna Castro GONDINHO: Universidade Estadual do Piauí - UESPI. ORCID:

https://orcid.org/0000-0002-1061-4407

\section{Resumo}

A interferência do poder judiciário em questões de competência dos poderes legislativos e executivos, tornou-se cada vez mais frequente após a aprovação da Constituição Federal Brasileira de 1988. A este novo papel para garantir os direitos individuais damos o nome de judicialização. A judicialização é a busca pelo sistema judiciário como a última alternativa para obtenção do medicamento ou tratamento ora negado pelo sistema de saúde público ou privado, seja por falta de previsão de estoque, seja por questões orçamentárias. É reflexo de um sistema de saúde deficitário, que não consegue concretizar a contento a proteção desse direito fundamental. A judicialização das políticas públicas evidencia a insuficiência do Estado em garantir a sua população o direito ao acesso às ações e serviços reconhecidos nas leis. À medida que o Estado deixa de cumprir com suas obrigações, embora constitucionalmente assegurado, a população recorre ao poder judiciário para reivindicar e garantir o acesso aos serviços negados. $\mathrm{O}$ direito à Saúde e a assistência social são uns desses direitos assegurados à pessoa idosa. $A$ Lei $n^{\circ} 10.741$, de $1^{\circ}$ de outubro de 2003, que dispõe sobre o Estatuto do Idoso, estabelece em seu capítulo IV, artigo 15. É assegurada a atenção integral à saúde do idoso, por intermédio do Sistema Único de Saúde - SUS, garantindo-Ihe o acesso universal e igualitário, em conjunto articulado e contínuo das ações e serviços, para a prevenção,

Recebido: 4 out. 2020 Aceito: 21 out. 2020

Autor de correspondência: Laís Cristina Barbosa dos Santos

lacristsanto@gmail.com

Conflito de interesses: Os autores declaram não haver nenhum interesse profissional ou pessoal que possa gerar conflito de interesses em relação a este manuscrito. promoção, proteção e recuperação da saúde, incluindo a atenção especial às doenças que afetam preferencialmente os idosos. A mesma Lei ainda dispõe sobre o direito a assistência social em seu capítulo VIII, artigo 33. A assistência social aos idosos será prestada, de forma articulada, conforme os princípios e diretrizes previstos na Lei Orgânica da Assistência Social, na Política Nacional do Idoso, no sistema Único de Saúde e demais normas pertinentes. A política nacional do idoso tem como finalidade assegurar os direitos sociais do idoso, criando condições que promova sua autonomia e integração e participação da sociedade. Segundo ainda essa lei, é considerado idoso a pessoa com idade igual ou maior de sessenta anos. Diante do exposto, tendo como referência o aumento do envelhecimento populacional e o aumento da sobrevida individual, acarretou-se o aumento das doenças crônico-degenerativas. Com isso, o número de idosos com limitações funcionais físicas e/ou mentais tende a aumentar, tendo como consequência, independência e a perda da autonomia. Ou seja, a demanda por cuidados informais e/ou formais e suporte social tendem a aumentar. O presente artigo visa identificar o que a literatura científica apresenta sobre a judicialização do acesso de idosos ao Sistema Único de Saúde - SUS e Sistema Único de Assistência Social - SUAS? Objetivo: Analisar as demandas judiciais por acesso ao SUS e SUAS. Identificar e descrever as demandas judiciais por acesso ao SUS e SUAS. 
ISSN 2179-6750

Método: O estudo trata-se de uma revisão integrativa da literatura. O Tipo de estudo empregado foi uma coleta sistematizada dos dados que consiste na construção de uma análise ampliada da literatura através de um profundo entendimento de determinado fenômeno com base em estudos anteriores, permitindo posterior criação de um domínio para apoiar discussões sobre métodos e resultados de pesquisas, bem como aponta a necessidade de realização de novos estudos. Este estudo parte do questionamento "O que a literatura científica apresenta sobre a judicialização do acesso de idosos ao SUS e SUAS?", bem como irá considerar como contexto o SUS e SUAS, para identificação do fenômeno de judicialização do acesso e terá como população os idosos. A seleção da literatura será realizada nas bases de dados da Biblioteca Virtual em Saúde (BVS). Com o intuito de definir os assuntos e recuperar artigos de interesse será utilizada a estratégia de busca tw: (tw:(Sistema Unico de Saude)) OR (tw:(assistencia social)) OR (tw:(saude publica)) OR (tw:(sistema unico de assistencia social)) AND (tw:(judicializacao)) OR (tw:(acesso)) AND (tw:(idoso)). Na busca vieram 109 publicações, nas quais serão aplicados o critério de inclusão - texto completo disponível, bem como serão excluídos os estudos que não abordem a judicialização do acesso ao SUS e SUAS. A busca será transposta para o programa COVIDENCE, que irá auxiliar em relação à retirada das duplicatas, às demais etapas de seleção e organização do fluxograma. Considerações finais: Foram selecionados os cruzamentos que apresentaram resultados mais expressivos na tentativa de responder à pergunta de pesquisa. A sintaxe final escolhida que mais se adequa pergunta de pesquisa foi: tw: (tw:(Sistema Unico de Saude)) OR (tw:(assistencia social)) OR (tw:(saude publica)) OR (tw:(sistema unico de assistencia social)) AND (tw:(judicializacao)) OR (tw:(acesso)) AND (tw:(idoso)). Na busca vieram 109 publicações, entre estes foram removidas 5 duplicatas; das104 publicações que sobraram, 57 foram excluídas na análise de título e resumo. Após análise dos artigos em texto completo, sobraram 5 artigos para realização de leitura na integra para análise reflexiva. Os demais resultados encontrados foram excluídos por não apresentarem relação direta com a pesquisa proposta.

Descritores: Judicialização da Saúde; Idoso; Sistema Único de Saúde; Serviço Social.

Keywords: Health's Judicialization; Aged; Unified Health System; Social Work.

Palabras-claves: Judicialización de la Salud; Anciano; Sistema Único de Salud; Servicio Social. 